\title{
Stresses in Bi-Layered NiO Scales
}

\author{
By Tokihiro Ueno*
}

\begin{abstract}
Different types of bi-layered scales of $\mathrm{NiO}$ can be formed in air on both sides of a thin nickel specimen at temperatures from 900 to $1200^{\circ} \mathrm{C}$. When the black/green bi-layer is formed on one side and the black/black bi-layer on the other, a flexure of the specimen ( $99.9 \%$ pure) is achieved during oxidation; the former is on the convex side. When removed electrochemically from the substrate of nickel ( 99 or $99.9 \%$ pure), the black/green bi-layer was elongated causing bending to the opposite side. On the contrary, the black/black bi-layer formed on the $99.9 \%$ pure nickel remained straight with a negligibly small elongation as compared with the black/green bi-layer. It is found that high compressive stresses occur in the green layer, and negligibly small stresses in the black/black bi-layer. Macroscopic elastic stresses in the green layer at room temperature are estimated to be the order of magnitude $10^{9}$ dynes $/ \mathrm{cm}^{2}$. Stress gradients across the scale are roughly estimated. Discussions are given of the formation of bi-layered structures.
\end{abstract}

(Received July 25, 1973)

\section{Introduction}

While the oxidation of pure nickel at high temperatures generally leads to the formation of a fully dense adherent oxide layer with a coarse columnar grain structure, oxidation of impure nickel or of pure nickel at lower temperatures forms a bi-layered structure comprising a columnar coarse-grained outer layer and a fine-grained porous inner layer ${ }^{(1) \sim(10)}$. The formation of the bi-layered structure is undesirable since it leads to a breakdown of scale, thereby lowering the oxidation resistance of the nickel ${ }^{(8) \sim(10)}$.

On the basis of Pt-marker measurements, some investigators have reported that the porous inner layer is formed by the inward diffusion of oxygen and takes the place of the consumed metal ${ }^{(2)(3)(11)(12)}$ : On the contrary, others have cast doubt on the conclusion of the Pt-marker measurements ${ }^{(5)(13)(14)}$. If this inward diffusion of oxygen occurs really, tensile or compressive stresses are expected to arise during oxidation depending on the oxide/metal volume ratio ${ }^{(15)}$. In a series of studies, on the other hand, the development of the bi-layered structure has been ascribed to the nondiffusion-controlled factors such as grain size, porosity, impurities and, especially; inhibition of plastic deformation during oxidation ${ }^{(5)(8) \sim(10)(16)(17)}$ : Evans et al. have suggested that compressive stresses are generated in the porous inner layer ${ }^{(10)}$. It thus seems that the formation of the bi-layered structure is stress-dependent. However, the data on the stress measurements during the oxidation of nickel, which are possibly correlated to the bi-layered structure, are very scant.

Recently, the present author has reported that four types of bi-layered oxide scales are formed on both impure and pure nickel at high temperatures between 900 and $1200^{\circ} \mathrm{C}^{(18)}$. The bi-layer formed on impure nickel which comprises a black outer layer and a green

* Department of Applied Physics, Faculty of Engineering, Hokkaido University, Sapporo, Japan.

Trans. JIM inner layer is designated as the type " $R_{1}$ " or " $T_{1}$ " depending on their crystal orientations in the outer layer. Similarly, the bi-layer formed on pure nickel which comprises a black outer layer and a green inner layer is designated as the type " $R_{2}$ ". The outer layer of these three types of scale is dense and consists of coarse-columnar grains, while the inner layer is composed of fine-equiaxed grains. The bi-layer called the type " $T_{2}$ " is formed on pure nickel and consists of a black, coarse-columnar, outer layer and a black, coarse-noncolumnar, inner layer with a crystal orientation different from the former.

There are several techniques for measurements of stresses during the oxidation of metals, that is, X-ray ${ }^{(19)}$, optical ${ }^{(20)}$ and flexure techniques ${ }^{(21) \sim(25)}$. In the flexure techniques, generally, bending of a thin metal specimen oxidized unilaterally is observed and macroscopic elastic stresses are evaluated. In the present experiments a modified flexure technique is presented and the results are correlated to the four types of the bi-layered structures. The origin of the bi-layered structures is also discussed.

\section{Experimental Procedure and Results}

Stresses caused during oxidation was calculated from a flexure shape of a thin rectangular nickel specimen. Further information about stress distribution along its cross-section was obtained from elongation and flexure of oxide scale resulting from the removal of the nickel substrate.

Starting materials were 99 and $99.9 \%$ pure nickel. Impurity elements in these materials have already been listed elsewhere ${ }^{(18)}$. They were cut into coupons approximately $1.4 \times 0.25 \mathrm{~cm}$ with a thickness of $0.45 \pm 0.01 \mathrm{~mm}$ or above $(1.4 \times 0.25) \mathrm{cm}$ with a thickness of about $1 \mathrm{~mm}$. These specimens were composed of crystallites nearly randomly oriented. Details of surface treatments and their effects on the bi-layered structures were described previously ${ }^{(18)}$. One side of a specimen was polished mechanically with a carbo-

1974 Vol. 15 
rundum powder of No. 1000 and the other side with fine alumina abrasives to a mirror. After mechanical polishing some specimens were subjected to elestropolishing. In order to remove strains, nickel specimens were annealed in a $10^{-5}$ Torr vacuum at various temperatures from 500 to $1000^{\circ} \mathrm{C}$ for a few hours. The specimen was mounted through a Pt-wire in an electric furnace. The oxidation was carried out in air at various temperatures from 900 to $1200^{\circ} \mathrm{C}$. Temperatures during oxidation were maintained constant within $\pm 5^{\circ} \mathrm{C}$. Surfaces of the $99.9 \%$ pure nickel specimen polished mechanically led easily to the formation of the different types of scale: The type $T_{2}$ scale was formed on the mirror-like surface and the type $\mathbf{R}_{\mathbf{2}}$ scale on the irregular surface polished with the carborundum powder. As electropolishing was proceeded, the irregular surfaces were liable to the formation of the type $T_{2}$ scale. Only by chance, the type $R_{1}$ and $T_{1}$ scales were grown on both sides of a $99 \%$ pure nickel specimen, respectively. It should be noted that the ratio of the thickness between the black and the green layers of the type $R_{2}$ scale varied to some extent depending on the temperature and the period of annealing.
Photograph 1(a) shows a $99.9 \%$ pure nickel specimen, $0.45 \mathrm{~mm}$ thick, oxidized at $1170^{\circ} \mathrm{C}$ for $60 \mathrm{hr}$. The presence of high stresses caused during oxidation is apparently recognized in its flexure shape. On the convex surface a bi-layer belonging to the type $R_{2}$ is formed (Photo. 1(b)), and a bi-layer belonging to the type $\mathrm{T}_{2}$ on the concave surface (Photo. $1(\mathrm{c})$ ).

For flexure measurements one end of the specimen was fixed through the Pt-wire and the position of the other free end was recorded by means of a cathetometer focused through a hole in the furnace at right angles to the reaction tube. The fixed point was adjusted to be $1.0 \mathrm{~cm}$ in length from the free end. Throughout the present experiments the effective specimen geometry was in a four-to-one length-to-width ratio. Cooling to room temperature revealed almost no change in the position of the free end, as reported by Tylcote ${ }^{(24)}$. Results of such flexure measurements on the $99.9 \%$ pure nickel specimen, $0.45 \mathrm{~mm}$ thick, oxidized at various temperatures are presented in Fig. 1 ; deflections from the original position are plotted as a function of the thickness of the scale. The thickness of the scale was measured with a photomicroscope. It appears that the flexure is independent of the tem-

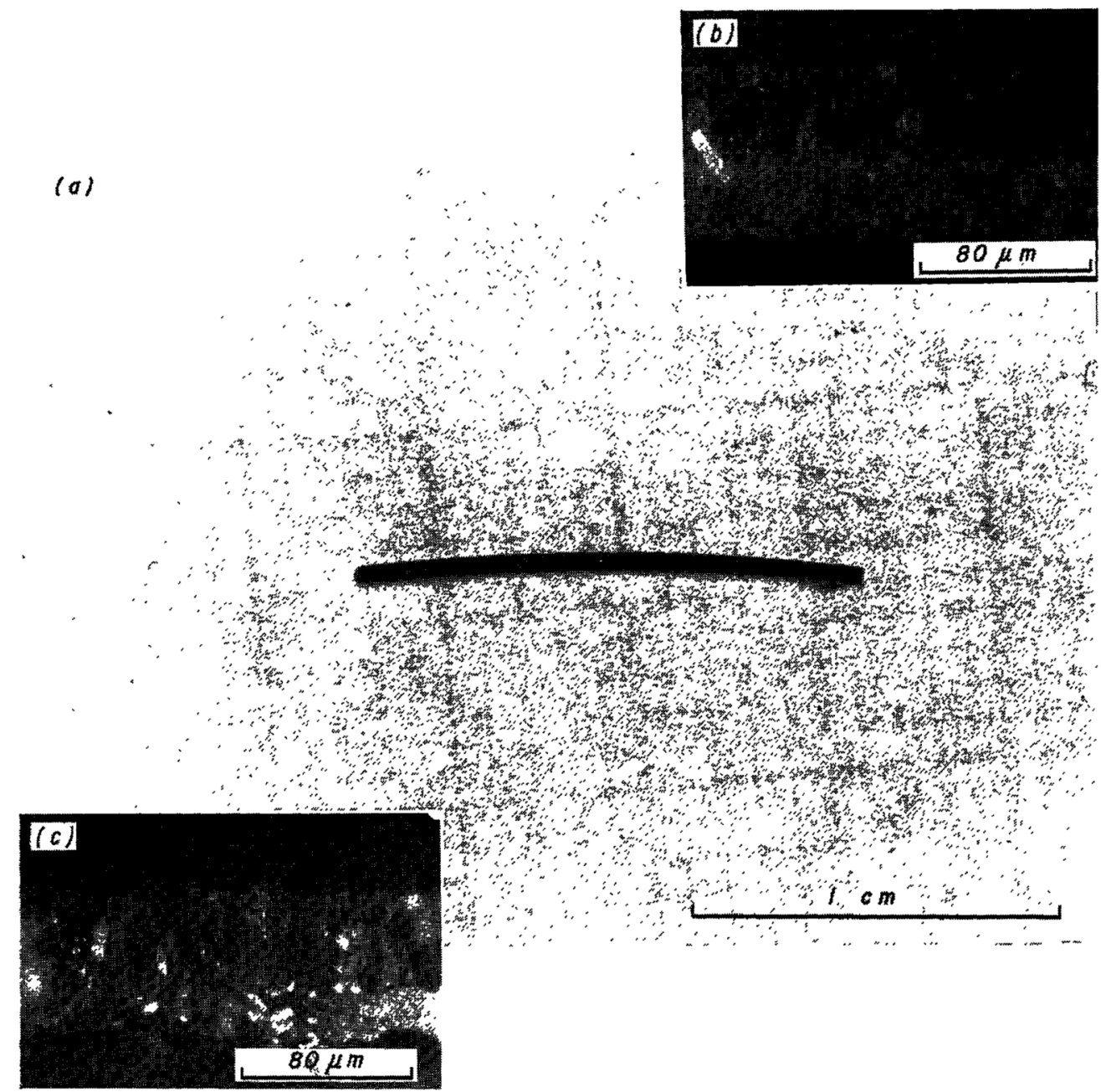

Photo. 1 (a) Nickel specimen $\left(99.9 \%\right.$ pure) oxidized in air at $1170{ }^{\circ} \mathrm{C}$ for $60 \mathrm{hr}$; view from the lateral side, and fractured cross-sections of oxide scales; (b) the duplex structure, a black outer layer and a green inner layer, formed on the convex side and (c) the duplex structure, a black outer layer and a black inner layer, formed on the concave side. Dimension of the nickel specimen: $1.4 \times 0.25 \times 0.045 \mathrm{~cm}$, where the effective length is $1.0 \mathrm{~cm}$ from the free end to the fixed point. 
perature of oxidation and the difference in thickness between the type $R_{2}$ and $T_{2}$ scales. It seems that the

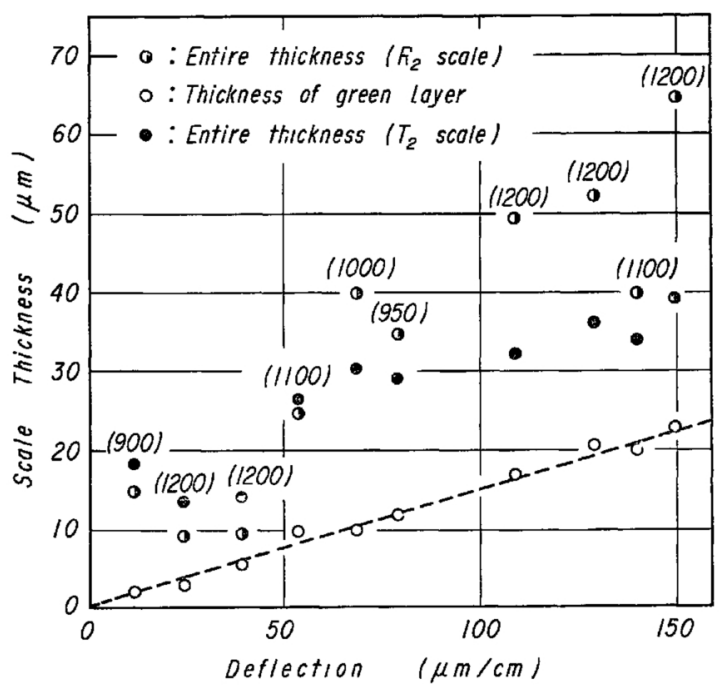

Fig. 1 Relation between the scale thickness and the deflection of the free end of the thin nickel specimen $(99.9 \%$ pure) during oxidation in air between 900 and $1200^{\circ} \mathrm{C}$; values in parenthesis are temperatures during oxidation. Dimension of the nickel specimen; $1.0 \times 0.25 \times 0.045 \mathrm{~cm}$. deflection is proportional to the thickness of the green layer. The $99 \%$ pure nickel specimen had no indication of flexure, even though the different types of scale were formed on both sides of the specimen. It is to be remembered that the type $R_{1}$ scale has a bi-layered structure similar to the type $T_{1}$ scale except for the crystal orientation of the black outer layer.

When the $99.9 \%$ pure nickel specimen about $1 \mathrm{~mm}$ thick was polished mechanically as mentioned above and then oxidized, its flexure shape was hardly detested (Photo. 2(a)). After the oxide scales on the lateral sides were polished mechanically, the metal substrate was dissolved away in a saturated $\mathrm{KCl}$ solution $^{(26)}$. Photograph 2(b) shows oxide scales removed from the $99.9 \%$ pure nickel specimen after oxidation for $15 \mathrm{hr}$ at $1100^{\circ} \mathrm{C}$. Their cross-sections also are presented in the photograph. The type $R_{2}$ scale of $40 \mu \mathrm{m}$ thickness shows a flexure shape, while the type $\mathrm{T}_{2}$ scale of the same thickness remains nearly straight. The oxide/metal interface of the green layer is on the convex side. Similarly, the scales formed on the $99 \%$ pure nickel specimen showed a flexure shape when removed from the substrate nickel. Flexures of oxide scales with various thicknesses were measured with a traveling microscope. Deflections from the original

(0)

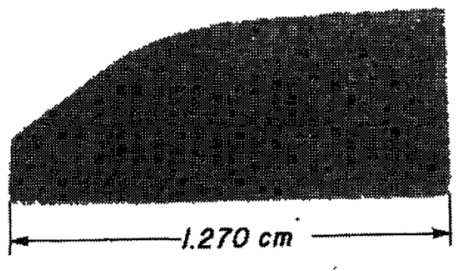

(b)

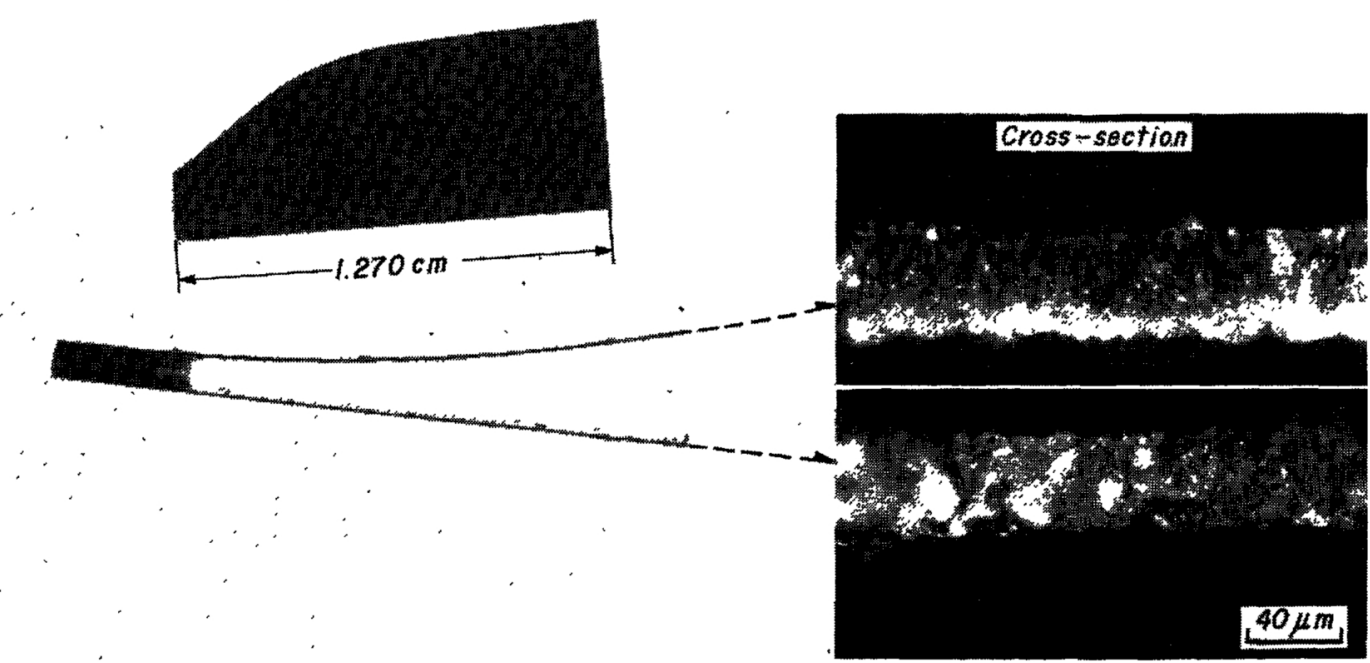

Photo. 2 (a) Nickel specimen $\left(99.9 \%\right.$ pure) oxidized in air at $1100^{\circ} \mathrm{C}$ for $15 \mathrm{hr}$ and (b) two types of NiO scales removed from the substrate by dissolving away metal; view from the lateral side. Fractured cross-sections of scales are shown. The specimen geometry is in a four-to-one length-to-width ratio. 
position per unit length of the scale are shown in Fig. 2. When black layers have the same in thickness, for example, 15 or $33 \mu \mathrm{m}$, deflections decrease with in-

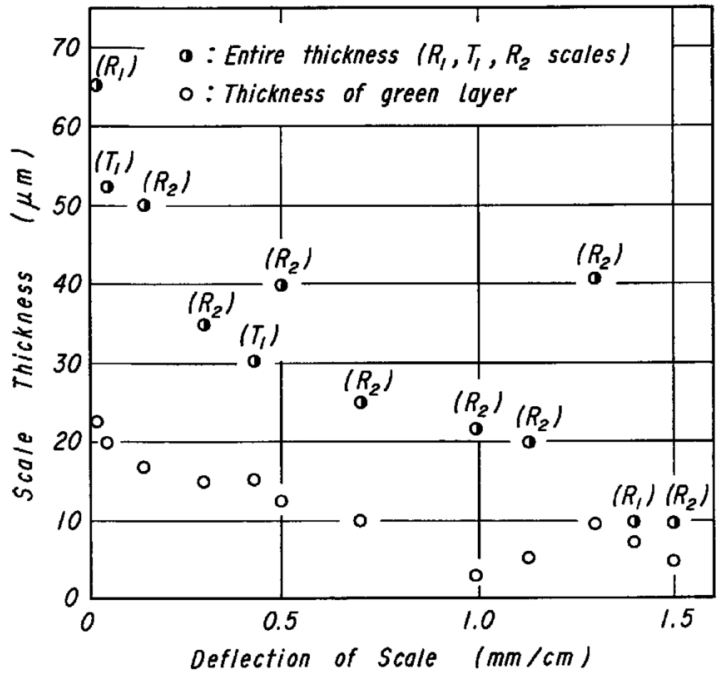

Fig. 2 Relation between the thickness of the black/ green bi-layer and the deflection of its free end per unit length of scale; the oxidation was carried out in air at various temperatures from 900 to $1200^{\circ} \mathrm{C}$ and then the scales were removed from nickel specimens ( 99 or $99.9 \%$ pure). The specimen geometry is in a four-to-one length-towidth ratio.

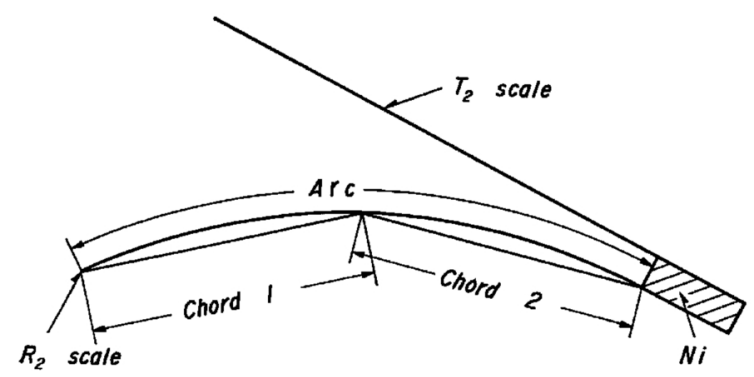

Fig. 3 Method for measuring the elongated flexure scale.

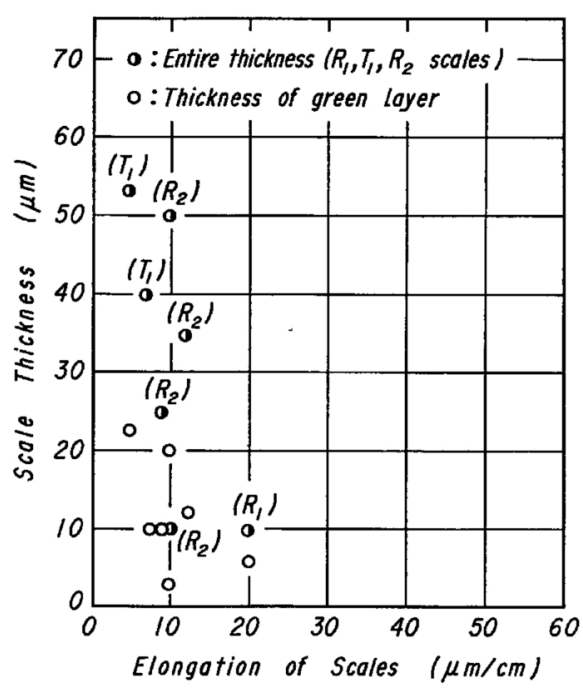

Fig. 4 Relation between the thickness of the black/ green bi-layer and its elongation; the oxidation was carried out in air at various temperatures from 900 to $1200^{\circ} \mathrm{C}$ and then the scales were removed from nickel specimens ( 99 or $99.9 \%$ pure). The specimen geometry is in a four-toone length-to-width ratio. creasing thickness of the green layer. It was difficult to detect the deflection of scale above $50 \mu \mathrm{m}$ in thickness.

It was also shown that flexure scales were elongated in length. They were divided into two chords, as shown in Fig. 3, and individual lengths were measured with the traveling microscope, because the actual length of the arc was estimated to be within $0.1 \%$ longer than the observed lengths of two chords. Figure 4 is a plot of the relation between the thickness and elongation of the scale. The elongation of the type $T_{2}$ scale was negligible as compared with the black/green bi-layer.

After having been polished in the mirror-like surface, three $99.9 \%$ pure nickel specimens were bent into a U-shape with a curvature of $1.0 \mathrm{~cm}$ radius, annealed in a $10^{-5}$ Torr vacuum, and oxidized at $1150^{\circ} \mathrm{C}$ for $24 \mathrm{hr}$. The bi-layer formed on the concave side showed a set of crystal orientations; in the outer and the inner layers the $\{311\}$ and the $\{111\}$ planes were parallel to the surface, respectively. On the contrary, the bi-layer formed on the convex side showed a different set of crystal orientations; in the outer and the inner layers the $\{100\}$ and the $\{110\}$ planes were parallel to the surface, respectively.

\section{Interpretation of the Results and Discussion}

The results of this investigation show that during the bi-lateral oxidation of nickel very high compressive stresses are caused in the surface layer by the formation of the bi-layered scales. In addition, the elongation and the flexure of the black/green bi-layer reveal that predominant parts of the stresses are formed in the green layer.

In the present work, upon cooling to room temperature, the bi-lateral oxidation of the thin nickel specimen makes up the difference between the thermal expansion coefficients of metal and oxide. In flexure techniques, flexure depends on the thickness of scale $^{(21) \sim(25)}$. However, deflections in Fig. 1 denote that the flexure of the nickel specimen is not caused by the difference in thickness between the type $R_{2}$ and $T_{2}$ scales.

Stresses in the thin nickel specimen $(99.9 \%$ pure) during oxidation is evaluated as follows. If a rectangular specimen is subject to uniform bending about one axis and if the materials obey Hooke's law, the compressive line force $S_{g}$ over the thickness of the green layer are given by the following formula ${ }^{(27)(28)}$ :

$$
S_{g}=\delta E_{\mathrm{Ni}} D^{2} / 3 l^{2},
$$

where $\delta$ represents the deflection of the free end from the original position, $E_{\mathrm{Ni}}$ Young's modulus of nickel, $D$ the thickness of the substrate, and $l$ the length of the specimen. Usually this equation is used to evaluate the internal stresses in the vacuum- or electro-deposited films on a thin substrate. Young's modulus of nickel at room temperature is $2.14 \times 10^{12}$ dynes $/ \mathrm{cm}^{2(29)}$. In this investigation $D$ contains the thicknesses of the substrate metal and the oxide scale. On the basis of Voigt's averages $^{(30)(31)}$, Young's modulus of $\mathrm{NiO}$ at room temperature is estimated at $2.77 \times 10^{12}$ dynes $/ \mathrm{cm}^{2}$. 


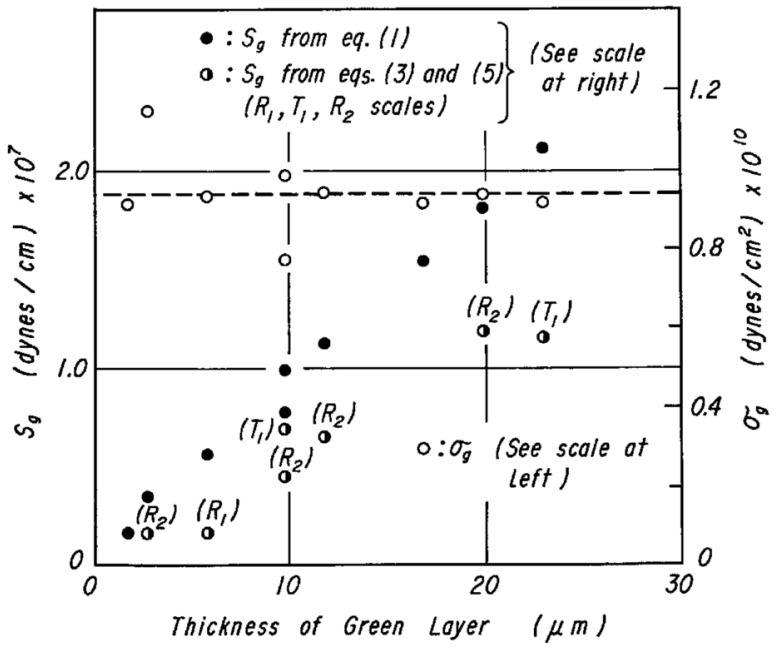

Fig. 5 Line forces over the thickness of the green layer and compressive stresses in the green layer.

$E_{\mathrm{NiO}}$ is about $30 \%$ higher than $E_{\mathrm{Ni}}$. The thickness of the black $\mathrm{NiO}$ scale is below $20 \%$ to the nickel substrate. Accordingly, the correction for Young's modulus of the substrate is approximated as below $0.2 \times 0.3$, that is, $6 \%$.

Stresses which exist as a result of a surface reaction are two dimensional in nature and the above-mentioned theory must be modified in order to take the deviation from cyrindrical flexure into account. The action of the lateral or Poisson strain components during even one-dimensional flexure of thin specimens is sufficient to alter the stress $S_{g}$ by a factor of $1 /$ $\left(1-v^{2}\right)^{(22)}$, where $v$ is Poisson's ratio. The Poisson's ratio of nickel is $0.336^{(29)}$. We have reported the results based on eq. (1) with the realization that the actual stresses may be higher by $11 \%$ or more. Compressive line forces over the thickness of the green layer are represented with solid circles in Fig. 5. Stresses per unit area of its cross-section are given by

$$
\sigma_{g}=S_{g} / d_{g},
$$

where $d_{g}$ is the thickness of the green layer. They are given in the figure with open circles. Approximately $S_{g}$ increases in proportion to the thickness and $\sigma_{g}$ at room temperature is evaluated to be greater than $(9.4 \pm 0.6) \times 10^{9}$ dynes $/ \mathrm{cm}^{2}$.

Solid lines in Fig. 6 represent the elongated black/ green bi-layer, where flexure is disregarded. Broken lines in Fig. 6 represent the black or the green layer

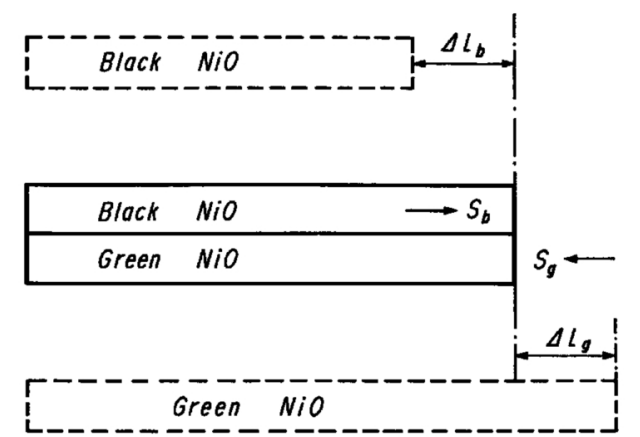

Fig. 6 Schematic diagram of strains in the black/green bi-layer which is removed from the metal substrate and is constrained from bending. which is stress-free. According to Hooke's law, the elongation of the black layer $\Delta l_{b}$ requires the tensile line force $S_{b}$ over the thickness $d_{b}$ of its layer, where

$$
S_{b}=E_{\mathrm{NiO}} \times \Delta l_{b} \times d_{b} .
$$

On the contrary, the contraction of the green layer $\Delta l_{g}$ requires the compressive line force $S_{g}$ over the thickness $d_{g}$ of its layer, where

$$
S_{g}=E_{\mathrm{NiO}} \times \Delta l_{g} \times d_{g} .
$$

When the black/green bi-layer is removed from the substrate metal,

$$
S_{b}=S_{g}
$$

Semi-solid circles in Fig. 5 represent $S_{g}$ calculated from eqs. (3) and (5). These values are approximately by a factor $2 / 3$ smaller than those from eq. (1). This discrepancy will remain as a subject of further study.

Deflections of the black/green bi-layer having the same thickness as that of the black outer layer increase with decreasing thickness of the green layer. This tendency suggests that the deflection of the scale is caused not only by the elongation of the green layer but also by the stress gradients which exist in the green layer. Estimated stress gradients are drawn schematically in Fig. 7. On the other hand, the establishment of defect gradients in the scale has been associated with stress gradients ${ }^{(32)}$.

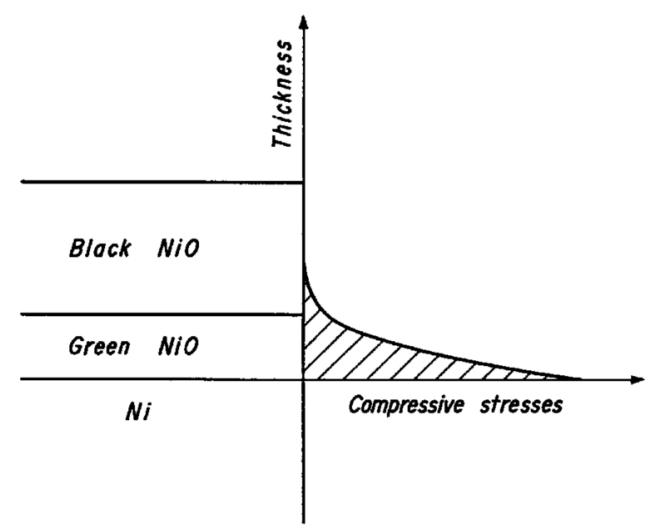

Fig. 7 Schematic diagram of stress distributions across the black/green bi-layer formed on the rigid specimen.

Evans et al. have pointed out that the oxidation of pure nickel below $1000^{\circ} \mathrm{C}$ leads to the formation of bi-layered structure because of inhibition of plastic flow in oxide ${ }^{(10)}$. In this investigation the black/black bi-layer and the black/green bi-layer were formed on a pure nickel specimen between 900 and $1200^{\circ} \mathrm{C}$, depending on the surface treatments. The origin of the above-mentioned stress distributions and the high compressive stresses in the green layer cannot be easily explained by the consideration presented by Evans et al.

Rhines and Wolf have pointed out that their bilayered structure depends on the curvature of the metal surface. Results of the U-shaped specimen in this investigation suggest that during oxidation stresses in the type $T_{2}$ scale are alleviated through the change of crystal orientation. 
In the present discussion the elastic and the plastic properties of the specimens during oxidation at high temperatures have been disregarded. Further details of the analysis of stresses and the growth mechanisms of the bi-layered $\mathrm{NiO}$ scales are presented elsewhere $^{(33)}$.

\section{Acknowledgments}

The author would like to express his sincere thanks to Prof. Y. Shimomura of University of Osaka Prefecture for many profitable discussion. He is also much indebted to Dr. T. Homma of Institute of Industrial Science, University of Tokyo, for providing many useful references.

Thanks are also due to Prof. N. Sato for his discussion and Prof. A. Odajima for his kindness throughout the work.

\section{REFERENCES}

(1) A. Preece and G. Lucus: J. Inst. Metals, 81 (1952), 219.

(2) J. A. Sartel and C. H. Li: J. Inst. Metals, 90 (1961), 92.

(3) B. M. Vasyutinskiy and G. N. Kartomazov: Fiz. Metal. Metalloved, 15 (1963), 132

(4) G. C. Wood, I. G. Wright and J. Ferguson: Corros. Sci., 5 (1965), 645.

(5) G. C. Wood and I. G. Wright: Corros. Sci., 5 (1965), 841.

(6) S. Morvec: Corros. Sci., 7 (1967), 563.

(7) D. L. Douglass: Corros. Sci., 8 (1968), 665.

(8) D. L. Douglass: Oxid. Metals, 1 (1969), 127.

(9) F. N. Rhines and J. S. Wolf: Met. Trans., 1 (1970), 1701.

(10) A. G. Evans, Dilip Rajdev and D. L. Douglass: Oxid. Metals, 4 (1972), 151.

(11) B. Ilschner and H. Pfeiffer: Naturwissenschaften, 23 (1953), 603.

(12) L. Czerski and F. Franik: Arch. Gorn. i Hutn., 3 (1955),
43.

(13) E. A. Gulbransen and K. F. Andrews: J. Electrochem. Soc., 105 (1958), 363.

(14) N. Terao: Japan. J. Appl. Phys., 10 (1971), 1256

(15) N. B. Pilling and R. F. Bedworth: J. Inst. Metals, 29 (1923), 529.

(16) A. Dravnicks and H. J. McDonald: J. Electrochem. Soc., 94 (1948), 139.

(17) T. Homma: Rept. Inst. Industr. Sci. Univ. Tokyo, 15 (1965), 165.

(18) T. Ueno: Trans. JIM, 14 (1973), 267.

(19) B. Borie, C. J. Sparks and J. V. Cathcart: Acta Met., 10 (1962), 691.

(20) J. V. Cathcart, J. E. Epperson and G. F. Petersen: Acta Met., 10 (1962), 699.

(21) P. D. Dankov and P. V. Churaev: Dokl. Nauk SSSR, 73 (1950), 1221.

(22) R. E. Pawel, J. V. Cathcart and J. J. Campbel: J. Electrochem. Soc., 110 (1963), 551.

(23) W. Jaenicke and S. Leistikow: J. Electrochem. Soc., 111 (1964), 1031.

(24) R. F. Tylecote: Mem. Scient. Revue Métall., LXII (May 15, 1965), 241.

(25) I. A. Menzies and P. Aldred: Corros. Sci., 8 (1967), 525.

(26) U. R. Evans and J. Stockdales: J. Chem. Soc., 131 (1929), 1651.

(27) G. G. Stoney: Proc. Roy. Soc., A32 (1909), 172.

(28) A. Brenner and S. Senderoff: J. Research Natl. Bur. Standards, 42 (1949), 105.

(29) W. P. Mason: Physical Acoustics and the Properties of Solids, Van Nostrand, (1958), p. 17.

(30) H. B. Huntington: Solid State Physics, Ed. by F. Seitz and D. Turnbull, Academic Press, Vol. 7 (1958), p. 317.

(31) P. de V. du Plessis, S. J. van Tonder and L. Albert: J. Phys. C, 4 (1971), 1983.

(32) R. E. Pawel and J. J. Campbell: Acta Met., 14 (1966), 1827.

(33) T. Ueno: To be published in Japan. J. Appl. Phys., Vol. 13, No. 5 (1974). 